\title{
DIAGNOSTICS OF PSYCHOPHYSIOLOGICAL POTENTIAL OF AGED PEOPLE
}

\author{
Svetlana Sokolovskaia, Elena Orlova \\ Lobachevsky State University of Nizhni Novgorod, Russia
}

\begin{abstract}
Development of psychophysiological potential of the person, in order to increase the quality and expectancy of life of employable aged people, involves the solution of an interdisciplinary tasks complex focused on the development of an innovative concept of diagnosis, analysis and development of psychophysiological potential of a person.

Aim of the first part of the research: Identification of the relationship between the physical activity and the cognitive processes development (for example, attention and memory).

Material and methods: We tested 84 people at the age of 54-65, engaged in various types of physical activity for a duration of up to two, five years or more. Their cognitive and coordination abilities were diagnosed with the usage of various techniques: Schulte's - stability of attention; Munsterberg's - concentration of attention; "Ten words" to determine the amount of attention; "Memory for numbers" for the diagnosis of short-term visual memory; test for associative memory; "Catching line" test for coordination abilities. The results were subjected to the correlation analysis. Results: Decreased attention stability and increased concentration and attention span were identified. It is especially noticeable in people, who are engaged in physical activity for more than two years. Indicators of visual and associative memory increase dramatically during physical activity, which a person has been practicing for more than two years, but with a duration of more than five years - gradually begin to decline. Coordination abilities are constantly increasing depending on the duration of an exercising period. In most cases, the correlations of cognitive and coordination abilities are weak.

Conclusion: Physical activity has a positive effect on the coordination and cognitive functions of elderly persons. But in addition to physical exercise, the training process requires some special cognitive functions activating tools.
\end{abstract}

Key words: elderly persons, physical activity, attention, memory, cognitive abilities.

\section{INTRODUCTION}

In the national doctrine of education of the Russian Federation, the development of a healthy lifestyle is called the strategic development goals of Russia until 2025 (National Doctrine of Education in Russian Federation, 2019.

The growth of psychophysiological disorders in human development significantly limits the quality and expectancy of life, prompting specialists to search for causes of deviations and factors ensuring the creation of favorable conditions for the formation of a healthy lifestyle and productive human activity in various fields throughout life.

Currently, European research focuses on the development of the concept of active longevity (activelongevity) and the implementation of a policy of active and healthy longevity as a valuable asset to society. It is impossible to ensure health and active longevity only by treating and even preventing diseases in its current sense. The need for a new, offensive strategy is obvious. Development of a technology, which will enhance the cognitive and physical reserves of an aging person, can become the core of it.

According to research and development of domestic and foreign scientists (Ananiev, 2006, Rubinshtein, Merlin, Nechaev, 2015, Skiridova, 2016, and others.; Adler, Maslow, Perls, Pedersen, 2015, Denham, (2016), etc.), the continuation of professional, physical and cognitive activity, an active and healthy lifestyle can significantly withstand the natural age changes in the body, can contribute to a significant increase in the efficiency of their use, to the development of the psycho-physiological potential of a person, can improve integral health, quality of life and lead to personal growth.

In view of the tendencies towards raising the retirement age, the task of preserving the health of the able-bodied population (especially at the ages from 50 to 65 ) has become significantly important. Solution to the problem of the working ability of people over 50 years will be found with the development of technology, which will enhance the cognitive and 
physical reserves of an elderly person, the basis of which may be the optimization of the integral resource concept of health.

Currently, researchers articulate the concept of health within one of four models of health:

1. Medical model - takes into account only medical signs and characteristics, health is considered to be the absence of diseases and symptoms (Daribazaron, Nechaev, 2015, Ivanova, et al.).

2. Biomedical model - considers the absence of organic disorders in a person and subjective feelings of ill health (Orlov, Fetisov, Strizhakova, Chekalova, Chekalova, Silkin, Mironova, Kozhevnikova, Azova, Azov, and others).

3. Biosocial model includes both biological and social aspects, with a priority of social ones Burenkov, et al, 2016, Vorobey, and others).

4. The value-social model assumes that health is a value for a person, a necessary prerequisite for a full life, satisfaction of material and spiritual needs, participation in work and social life, economic, political, scientific, cultural and other activities (Valiakhmetov, et al., (2017), Veselova, Anisimova, Zalevsky, 2015.)

The multilevel and multidimensional nature of the health phenomenon determines the interdisciplinary nature and wide dissemination of holistic, and now integral-value, integrative approach to human health issues (Khvatova, et al., 2015).

There are a large number of attempts to analyze and systematize the various concepts of the central categories of integral human health. Terminological controversy is focused on the discussion of the content of concepts such as mental health, mental, personal, social well-being, quality of life Ananyev, 2006 and his followers.

Modern scientific data, presented by statistical reports of medical institutions (Boccardi, Paolisso, Mecocci, 2016), indicate an increase in cases of health problems in people of the second (50 to 65 years) and third (65 years and above) categories of working age. In view of this, many researchers are focused on finding ways to prevent possi- ble diseases. The research results showed that the overwhelming majority of Russian and foreign authors (Pedersen, Saltin, (2015), Korzhova, et al., (2017), Nechaev, et al, (2015), Skiridova, (2016), Sokolovskaia, et al, (2017). The WHO basic mental health, human rights and law handbook. (2005) point out the huge role of motor activity in a person's lifestyle, the optimal level of which positively affects the state of human health.

The goal of the study: the fundamental task of the study is to identify patterns and mechanisms for maintaining a high level of health of an aging person, to establish the relationship of mental health parameters with the state of the physical, personal and social health. This part of the research is devoted to revealing the relationship between the level of physical activity and the level of development of cognitive processes (through the example of attention and memory) in people of the second able-bodied category (from 50 to 65 years).

\section{METHODOLOGY}

In the course of the study there were used: a theoretical method of analysis of literary sources, an empirical method of psychodiagnostic testing, questioning, methods of statistical data processing.

There were used following diagnostic methods as procedures: Schulte's attention span; Munsterberg's concentration of attention; volume of attention technique of "Ten Words"; short-term visual memory - technique of "Memory for numbers"; test for associative memory; test for coordination abilities "Catching a ruler" (according to the method of S.A. Dumanin). The reliability of the obtained results is determined by quantitative and qualitative analysis of experimental data. For statistical processing there were used methods of mathematical statistics - Brave-Pearson's correlation coefficient.

The study involved 84 people at the age of 54-65 years, engaged in various types of physical activity.

\section{ANALYSIS}

All tested were divided into 6 groups, depending on their age (54-59 years and 60-65 years) and the duration of physical activity trainings (up to 2 years, from 2 to 5 years and more than 5 years), information was collected using questionnaires. 
Table 1. Summary table of indicators of various parameters

of the integral human health for the studied groups

\begin{tabular}{|c|c|c|c|c|c|c|}
\hline $\begin{array}{c}\text { The results of the } \\
\text { methods (arithmetic } \\
\text { average) }\end{array}$ & $\begin{array}{c}54-59 \\
\text { years } \\
<2 \text { years } \\
\end{array}$ & $\begin{array}{c}\quad 60-65 \\
\text { years } \\
<2 \text { years } \\
\end{array}$ & $\begin{array}{c}54-59 \\
\text { years } \\
2-5 \text { years } \\
\end{array}$ & \begin{tabular}{|c|}
$60-65$ \\
years \\
$2-5$ years \\
\end{tabular} & $\begin{array}{c}54-59 \\
\text { years } \\
>5 \text { years } \\
\end{array}$ & $\begin{array}{c}60-65 \\
\text { years } \\
>5 \text { years } \\
\end{array}$ \\
\hline Attention span (seconds) & 56,15 & 55,17 & 38,74 & 40,77 & 40,78 & 42,42 \\
\hline $\begin{array}{c}\text { Attention concentration } \\
\text { (points) }\end{array}$ & 1,71 & 1,93 & 17,94 & 16,55 & 11,4 & 9,2 \\
\hline $\begin{array}{l}\text { Volume of attention } \\
\text { (correct answers) }\end{array}$ & 4,44 & 4,33 & 6,2 & 6,4 & 5,25 & 5,52 \\
\hline $\begin{array}{c}\text { Short-term visual memory } \\
\text { (correct answers) }\end{array}$ & 3,5 & 3,86 & 6,64 & 6,94 & 5,8 & 6,5 \\
\hline $\begin{array}{l}\text { Associativememory } \\
\text { (correctresponses) }\end{array}$ & 5,3 & 4,8 & 7,2 & 8 & 6,7 & 6,5 \\
\hline $\begin{array}{l}\text { Coordinationabilities } \\
\text { (centimeters) }\end{array}$ & 4,85 & 4,6 & 8,47 & 8,38 & 8,7 & 9 \\
\hline
\end{tabular}

According to the obtained data, the stability of attention is sharply reduced depending on the duration of physical activity, and this does not depend on specific age. People at the age of 54-59 years, who are engaged in physical activity for less than two years, are able to maintain attentiveness longer (average 56.15) than those engaged in such an activity for more than two years (38.74) and even more than 5 years (40.78). Similar trends are observed in the age group from 60 to 65 years. Perhaps this is due to the fact that at the beginning of learning motor actions, all students have to master new movements, since they have not yet developed a motor skill. During motor activity practicing, a person masters the technique of performing movements, motor skill is formed, respectively, his attention is released, the need to focus it for a long time disappears.

At the same time, it becomes necessary to focus on external circumstances in which physical activity is involved, i.e. if it is sports (mobile) games - attention should be focused on a specific game situation, if it is gymnastics or Nordic walking, which is very popular among the elderly now, - on the objectives of the exercise or the environment. Consequently, such indicators of attention as concentration and volume, constantly increase. This is especially noticable for those who practice for more than two years (at the age of 54-59 years, the average indicator is 17.94 , at the age of $60-65$ years - 16.55) as compared to those who practice for less than two years (at the age of 54-59 years it is, 71 , at the age of 60-65 years -1.93$)$.
Similar trends are observed in relation to memory. Physical activity requires the development of shortterm visual memory, as well as associative memory in mastering the technique of movement - for the formation of motor skills. This is evidenced by the indicators of a sharp increase in the volume of visual memory for those engaged in physical activity for more than two years: at the age of 54-59 years from 3.5 to 6.64 , at the age of $60-65$ years - from 3.86 to 6.94 . When doing physical activity for more than five years, these indicators begin to decline. The reason for this, apparently, is the fact that the motor skill has already been formed, and new goals for its use are not set, i.e. startup and situational afferentation becomes habitual for those involved, and the need to actively use visual and associative memory goes away.

The development of coordination skills is associated with the formation of a motor skill depending on the duration of the lessons of motor activity. The data indicate an inevitable increase in performance: at the age of 54-59 years from 4.85 with less than two years of practice, to 8.47 - more than two years and up to 8.7 - with more than five years of practice; at the age of 60-65 years old - from 4.6 with less than two years of practice, up to 8.38 - with more than two years of practice and up to 9 with more than five years of practice.

During the comparison of selected indicators of integral health of a person at the age of 54-59 years and 60-65 years, no significant differences were found, consequently, the development trends of se- 
lected skills are preserved in the elderly at the age of 54 to 65 years, regardless of the age.

The correlation analysis of the research results was carried out using the Brave-Pearson correlation coefficient for all previously selected 6 groups of students (Table 2).

Table 2. Dependence between the indicators of coordination and cognitive abilities of the elderly

\begin{tabular}{|c|l|l|l|l|l|l|}
\hline \multirow{2}{*}{ Testing methods } & \multicolumn{5}{|c|}{ Coordination skills of groups } \\
\cline { 2 - 7 } & $\begin{array}{c}\mathbf{5 4 - 5 9} \text { years } \\
\text { <2 years }\end{array}$ & $\begin{array}{c}\mathbf{6 0 - 6 5} \text { years } \\
<\mathbf{2} \text { years }\end{array}$ & $\begin{array}{c}\mathbf{5 4 - 5 9} \text { years } \\
\mathbf{2 - 5} \text { years }\end{array}$ & $\begin{array}{c}\mathbf{6 0 - 6 5} \text { years } \\
\mathbf{2 - 5} \text { years }\end{array}$ & $\begin{array}{c}\mathbf{5 4 - 5 9} \text { years } \\
\mathbf{5} \text { years }\end{array}$ & $\begin{array}{c}\mathbf{6 0 - 6 5} \text { years } \\
>\mathbf{5} \text { years }\end{array}$ \\
\hline Attention span & 0,15 & 0,12 & 0,26 & 0,14 & 0,31 & $-0,033$ \\
\hline $\begin{array}{c}\text { Attention } \\
\text { concentration }\end{array}$ & 0,018 & $0,51^{* *}$ & $-0,21$ & $-0,18$ & 0,33 & $0,78^{* *}$ \\
\hline $\begin{array}{c}\text { Volume of attention } \\
\text { Short-term visual } \\
\text { memory }\end{array}$ & 0,08 & 0,08 & $-0,31$ & 0,02 & $-0,06$ & $-0,21$ \\
\hline Associative memory & $-0,28$ & 0,05 & 0,4 & $-0,02$ & 0,22 & $-0,09$ \\
\hline
\end{tabular}

Note: ${ }^{*}-1<r<-0.5$ Strong negative correlation; $-0,5 \leq r<0$ Weak negative correlation; $0<r \leq 0.5$ Weak positive correlation; ${ }^{* *} 0.5<r<1$ Strong positive correlation

Correlation coefficients have different directions. Concentration of attention indicators are in a strong direct dependence with the coordination abilities of those who are engaged in physical activity at the age of 60-65 years and who practice such an activity for less than two and more than five years. Associative memory has a feedback with the coordination abilities of those who are engaged in physical activity at the age of 54-59 years and who practice such an activity for less than two and more than five years. The remaining dependencies are not significant. The establishment of correlation links allows us to assume that physical activity has a positive effect on the development of not only coordination abilities, but also of cognitive functions of elderly people, in particular, attention and memory. At the same time, the presence of the majority of poorly noticable correlations suggests that cognitive abilities cannot be developed only by means of physical activity. Therefore, in order to preserve the integral health of a person over the age of 50 , it is necessary to use special exercises aimed at enhancing cognitive functions during physical activity.

\section{CONCLUSION}

It has been established that physical activity has a positive effect on the coordination and cognitive functions of the elderly. But apart from physical exercises, the inclusion in the training process of means of activating cognitive functions is required. The study of coordination and cognitive abilities showed their high information content in the assessment of the integral health of elderly people. Further challenges in enhancing the reserves of the working population over 50 years are outlined.

This study is a starting point in the creation of an integral resource concept of health of an elderly person. The next subtask is to identify the parameters of physical and mental health depending on the requirements of specific professions of the able-bodied citizens over 50 years, creation of technology on this basis, which will enhance the cognitive and physical reserves of the aging population.

\section{REFERENCES}

Boccardi, V., Paolisso, G. and Mecocci, P. (2016). Nutrition and lifestyle in healthy aging: the telomerase challenge, World Biomedical Frontiers - Aging, V8, №1, pp. 5-12.

Denham, J., O’Brien, B.J., Charchar, F.J. (2016). Telomere length maintenance and cardio-metabolic disease prevention through exercise training, Sports Medicine, 2016, V.46, № 9, pp 1213-1237. 
Pedersen, B.K., Saltin, B. (2015). Exercise as medicineevidence for prescribing exercise as therapy in 26 different chronic diseases, Scandinavian Journal of Medicine and Science in Sports, 2015, V25, №3, pp.1-72.

Ananiev, V.A. (2006). Basis of health psychology St. Petersburg, Rech Publ.

Zalevsky, G.V. (2015). Integral-value paradigm and biopsychosocionoetic model of human nature and health in the context of positive anthropological psychology. Siberian Psychological Journal, 2015, no. 58, pp. 100-108.

Korzhova, E.Yu., Veselova, E.K., Anisimova, T.V., Zalevsky, G.V. (2017). The integral resource conception of health in the context of domestic approaches, Reviewof A.I. Herzen Russian State Pedagogical University, 2017, no. 184, pp. 31-44.

National Doctrine of Education in Russian Federation [URL]: http://www.zdcollege.ru/docs/vospitanie/patriot/nr-f-doctrina.pdf (accessed 21.02.2019)

Nechaev, V.S., Ivanova, L.G., Babchenko, Yu.V., Migachev, D.V. (2015). The substantiation of a complex integral approach to human health and the society, Bulletin of N.A. Semashko National Research Institute of Public Health, 2015, no. 2, pp. 172-174..

Skiridova, A.S. (2016). The role of physical culture in human health, Training and education: methods and prac- tice, 2016,no. 27, pp. 122-126..

Sokolovskaia, S.V., Paoli, A., Bulova, T. V., Umnov, A. L., Orlova, E. A., Sokolovsky S. V. (2017). Development of technology to activate cognitive and physical reserves of a person using the "Active longevity» complex under the conditions of the demographic transition caused by the increase in life expectancy of people, proceedings of the XVI international scientific and practical conference "Optimization of the training process», 2017. pp. 426-431. Sochen, G.T., Lopatina, A.B. (2016). Integrated approach to human health concepts, Successes of modern science and education, 2016, vol. 7, no. 10, pp. 68-70.

The WHO basic mental health, human rights and law handbook. (2005).

Tsarkova, N.I., Vorobey, O.V. (2016). Actual problems of integral assessment of public health, Actual problems of the humanities and natural sciences, 2016, no. 3-6, pp. 92-96.

Corresponding author: Svetlana Sokolovskaia

$\mathrm{PhD}$, associate professor, Lobachevsky State University of Nizhni Novgorod, Russia E-mail: kuzminasv2013@inbox.ru 